\title{
SIMULATION OF MULTIMODAL LOGISTICS NETWORKS
}

\author{
Christian Hillbrand and Susanne Schmid \\ V-Research GmbH \\ Industrial Research and Development \\ Stadtstrasse 33, 6850 Dornbirn, Austria \\ E-mail: christian.hillbrand@ v-research.at, susanne.schmid@ v-research.at
}

\section{KEYWORDS}

Co-operative logistics models, simulation, green logistics, multimodal transport.

\begin{abstract}
The partly outsourcing of value creation processes to low-wage countries yields opportunities to cut manufacturing costs dramatically on one hand. On the other hand, these companies incur higher logistics costs due to an increased logistical complexity. Usually the transportation processes are planned in an ad-hoc manner on a local basis. Consequently one can observe a huge majority of all goods being transported directly from plant to plant by unefficient means of transport. One solution for this dilemma would be the joint usage of multimodal logistics systems which is very often inhibited by the need for close cooperation and high coordination efforts. In order to facilitate this process, this paper proposes an approach to use discrete event simulation for supporting the evaluation of different layouts of multi-company multimodal logistics systems. The novelty of this technique is the opportunity to analyze multiple dimensions of a given complex logistics scenario. By contrast to known analytic techniques the methodology not only captures the economic aspect of this issue but is also able to evaluate the ecological and logistical perspective.
\end{abstract}

\section{INTRODUCTION}

As one trend of the globalized economy, manufacturing companies are outsourcing non-core parts of their valuecreation processes to low-wage countries whereas at least the final assembly of goods remains at the original production sites. One effect of such decentralized manufacturing processes is that production costs can be cut dramatically (Kinkel et al 2004; Sihn et al. 2006). Hence, Central and Eastern Europe (known as CEE) became a popular target for relocation. These new production sites often just assume the supplier and customer structures of the parent plants. As figure 1 shows, approximately two thirds of suppliers as well as customers of Eastern European Tier 1 suppliers are still situated in Western Europe (Sihn et al. 2009).

However, benefits tend to fall short of predicted cost advantages, due to rising wage costs (in particular in industrial regions). The automotive industry in particular is thus focusing on the costs of transport logistics arising from intense transportation between Eastern and Western Europe.

The trend towards relocation has shown that the exchange of goods leads to new demands and challenges for transportation and logistics (Feldmann et al. 1996). Business networking strategies and especially crosscompany co-operation is one of the key factors to improve in production issues as well as in logistics and hence to survive in competitive markets (Kinkel et al. 2004; Wiendahl \& Lutz 2002).
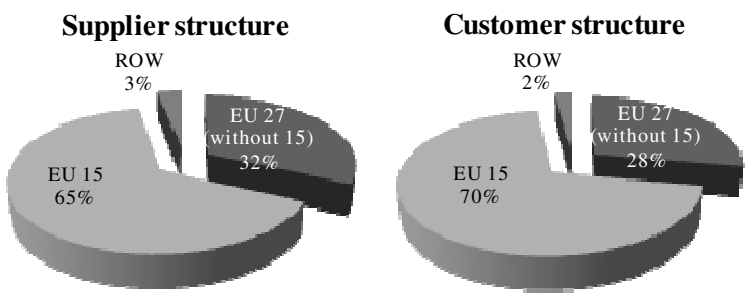

Figure 1: Demonstration of supplier and customer structure of suppliers in the CEE region

Based on this situation, a new simulation and evaluation model, which supports the development and evaluation of new logistics concepts, was developed. It is used for the validation and evaluation of cross-company logistics models. Due to the new, holistic evaluation approach potentials for optimization in the areas of emissions, costs and logistical competitiveness are targeted on developing new sustainable and energy-efficient logistics models.

\section{FORMAL MODEL OF MULTIMODAL LOGISTICS CHAINS}

The currently applied logistics processes, especially for the specific needs of individual enterprises in automotive industry, do not appear optimal from a holistic point of view. Deficits might emerge from direct transport running far beyond capacity, use of small transport carriers, less-than container load (LCL) with long running times or multiple handling steps as well as bad transportation tariffs due to small quantities. High stocks and capital tied up are results of this inefficiency. Since many companies have a similar source-targetbehavior the potential of cross-company bundling to optimize transport efficiency is high.

There are various approaches for cross-company logistics models that conform to the general network 
model of logistics. These models represent networks transporting laws, goods, finance and information where spatial, quantitative, informational and temporal differences as well as company boundaries are crossed (Vahrenkamp 2007). Parameters defining the structure of a logistics network are paramount (Rösler 2003):

- Number, locations and functions of source points (= loading locations, making goods available),

- Number, locations and functions of target points (= unloading locations, points of reception),

- Number, locations, functions of connections or nodes between sources and targets.

The network nodes are called transshipment terminals. This implies that only transshipment but not storage in general (no inventory) is foreseen at these locations. Transshipment terminals serve as consolidation terminals where the flows of goods are collected and/or as break-bulk terminals where the flows are in turn distributed (Rösler 2003). The basic structure of transportation links can be represented either as direct connection ("point-to-point" transport) in its simplest form (single-stage, uninterrupted transport chain) or as a multi-stage system with preliminary leg, main leg and subsequent leg with transshipment terminals where the network nodes serve as consolidation terminals where the flows of goods are collected and/or as break-bulk terminals where the flows are in turn distributed.
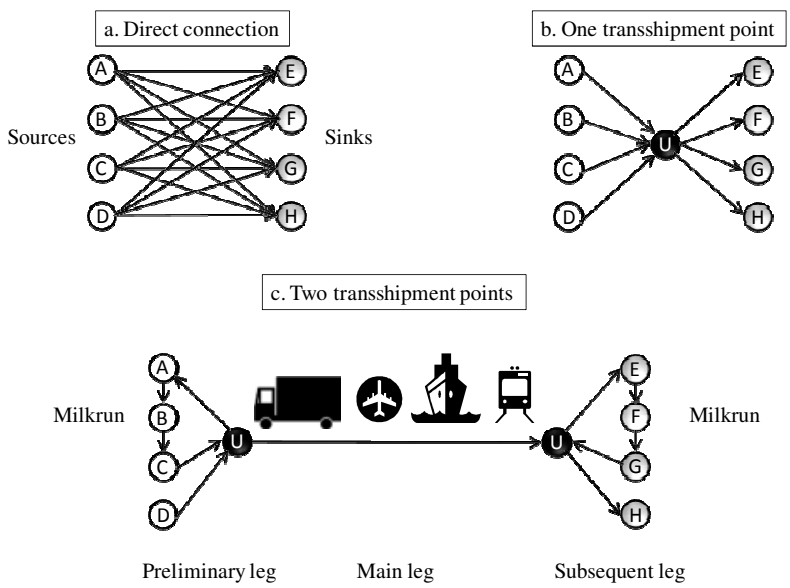

Figure 2: Illustration of consolidation by means of transshipment points (Brauer 1982).

The mixture of logistics systems made up from the given basic structures is decided in the logistical network structure. The processes are designed when the logistical capacities are superimposed on this. The logistical capacity can be subdivided into transport capacity, warehousing capacity and information capacity. In addition to the basic structure of the systems, the speed of traffic flowing between the individual points in the system must be taken into account (Pfohl 2004). The network strategy is also based on geo-economic considerations such as the long-term development of customer demand or the development of the required delivery time.

Summing up, the criteria logistics costs, supply service, adaptability, susceptibility to interference, transparency and time for planning and establishment of the system are important in the moment of developing and evaluation logistics models (Pfohl 2004).

As described in the initial situation, optimization of transports for individual businesses does not appear ideal; therefore companies can align with partners to a logistical cooperation and bundle transport volumes. Bundling, also referred to as consolidation, happens when transport volumes are combined to form larger transport batches in order to allow more efficient and more frequent shipping by concentrating large flows onto relatively few links between terminals, thus lowering transport unit costs and the unit costs of incoming or outgoing goods at their starting or target points. The starting points for the scenarios for transport bundling are the individual parameters of the logistical network structure. The following forms may thus be used:

- Source-point bundling often following the principle of the "milk run" (the shipments intended for a particular destination are collected from several places of shipment, from neighboring places of shipment or from a shipment region and processed together).

- Target-point bundling, where shipments from one place of shipment intended for several destinations or for a delivery region are processed jointly and transported together.

- Transport bundling, where shipments are collected and delivered in one tour.

Further forms of bundling can be inventory bundling or temporal bundling, and vehicle bundling and transshipment point or transit terminal bundling as forms of spatial bundling (Figure 2). The number of transports between sources and targets can be reduced by the setup of transshipment points from $\mathrm{m} \times \mathrm{n}$ to $\mathrm{m}+\mathrm{n}$, $\mathrm{m}$ and $\mathrm{n}$ being the number of source and target points (Campbell 1990; Simchi-Levi et al. 2007).

Bundled transport over the long run between 2 transshipment points can raise high potentials due to low transport costs and efficient use of transport capacities (Trip \& Bontekoning 2002). Logistic performance is improved by the raised frequency of transports. Overall every bundling type must meet the requirements of savings through consolidation of synergy effects to cover higher transport costs, operation costs of handling points or longer distances of time frames in comparison with direct relations.

The goal of reducing logistics costs while keeping logistics quality at the same level or raising the quality (delivery times, adherence to delivery schedule) is the main focus when designing the transport network. An iterative method is needed to evaluate the impacts of modifications in logistics models regarding ecology, economy or logistic competitiveness. 
Transport bundling or cross-company logistics networks are originally based on the idea of good distribution in urban centers. The different approaches can be summed up with the term city logistics (Taniguchi et al. 2001). Other known developments of transport bundling of different suppliers are area contract freight forwarders, bundling and delivering goods for one plant conjointly. Collaborative approaches and the logistics models in this case are mainly based on the following premises:

- Identification of route sections where transport volumes can be handled with efficient transport carriers.

- Availability of adequate partner for transport bundling on route sections (legs).

- Possibility of individual businesses to efficient usage of carriers.

- Distance from source to target of possible nodes considering impacts of variance from ideal path.

- Prioritization from transport volumes given limited capacities of one carrier in the main run as a result of different impacts on target categories.

- Possibility to change transport frequency.

\section{SIMULATION AND EVULATION MODEL FOR MULTIMODAL LOGISTICS CHAINS}

The analysis, evaluation, and comparison of the described multimodal logistics concepts for crosscompany bundling base on economical, ecological and logistical key performance indicators. Obtaining these indicators is affected by a multiplicity of factors and there exist numerous interdependencies between the parameters. The specification of a specific resource and a specific routing for instance have influence on each other and can have diverse impact on goal criteria. Beyond that, the identified parameters are in reality very often afflicted with uncertainty. These affects frequently influence the quality of material planning decisions and transport planning considerably. Owing to dynamic interactions and taking stochastic phenomena into account, a static estimation of the behavior is difficult or almost impossible. Simulation has satisfactorily demonstrated its ability to illustrate and evaluate systems with dynamic behavior.

For these reasons a simulation and evaluation model has been developed which allows system experts to model, analyze and evaluate co-operative multimodal logistics chains. The complete process of such a simulation study can be divided into several steps as shown in figure 3 . In the following chapters the steps model generation and simulation \& logging as well as result calculation and result analysis are described in detail.

\section{Conceptual design and automatic generation of the simulation model}

The model is implemented within the simulation environment Flexsim ${ }^{\circledR}$ (Nordgren, 2003). The conceptual design of the simulation model focuses on providing a generic, easily adaptable model which allows a quick and efficient modeling and analysis of multimodal transportation scenarios. For this reason individual logistics simulation modules (or classes) were developed which individually implement the behavior of the objects as well as the interaction with other objects. These classes include the previously described logistics concepts (point-to-point transportation, consolidation terminals, milkruns, etc.) and can be combined with other modules in order to build multimodal logistics chains.

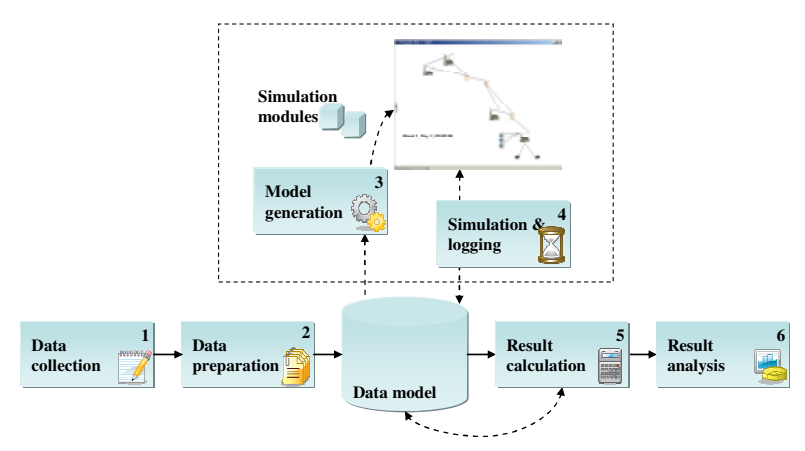

Figure 3: Steps of a Simulation Study

The central technical construct in the domain transport planning is the route, which represents a given startdestination-relation, for example between a loader in Eastern Europe and a Western European manufacturing facility. This route has one or several transport resources of various types assigned and either implements a direct relation or an intermodal transport, which is usually routed through certain transshipment points. The simulation model can be automatically generated by dropping route-objects into to simulation environment as illustrated in figure 4.

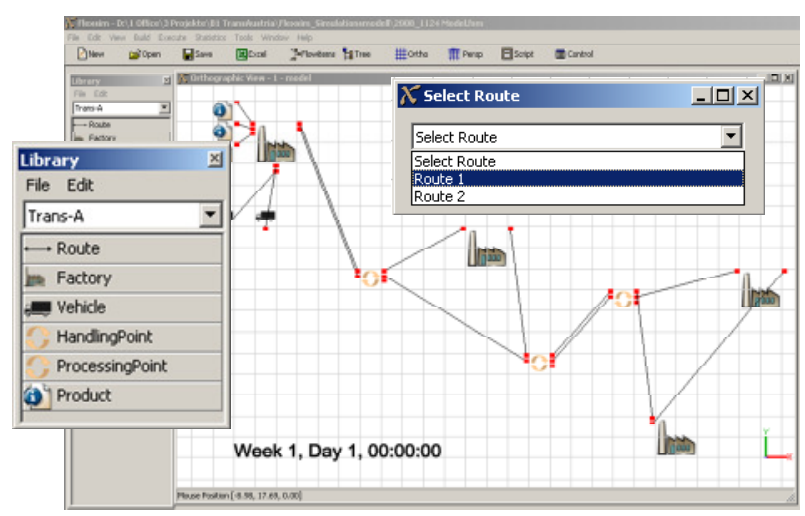

Figure 4: Generation of a simulation model by Drag\&Drop

A route defines the structural data of the model like number and types of plants, transshipment points or transport resources, or the connection between the simulation classes. This information is stored in a database. The behavior of the objects during the simulation run is implemented in the simulation 
modules. The classes are automatically created, parameterized, and connected with each other when a route is dropped into the model. The simulation classes include the following:

- Product: The system load of the simulation model is determined by the output of products on the consignor's side, which is being processed in form of a tabulated production schedule.

- Plant/Factory: A plant serves as a starting point (source) to add products or as a destination to discharge items from the transport (sink). Product objects are created as flow items in the course of simulation, beginning at the starting plant.

- Vehicle/Transport resources: Transport resources are active parts within the simulation model. They can be defined as various resource types like trucks or trains.

- Handling Point: A handling or transshipment point defines a point on the route where the flows of goods are collected and consecutively assigned to the outgoing transports. This means, the whole transport resource is unloaded and the goods are temporarily stored at the handling point for further transportation.

- Processing Point: By means of processing points the transports can be delayed at certain locations on the route. For instance the time-consuming customs handling between frontiers can be modeled as a processing point.

With this modeling structure changes to the simulation parameters (varied transport cycles, use of various transport resources, etc.) can be easily made and a comparison of the effects can be analyzed with the evaluation model which will be discussed below.

\section{Simulation Run and Data Logging}

After the creation and parameterization of the generated simulation classes, the simulation run can be initiated. The process starts off with the creation of products at the starting points according to the defined production schedules (see figure 5). These generated flow objects have to be transported on the defined routes by the previously assigned transport resources to the destination plants, where they are destroyed. The transportation process is planned, when a specified amount of products is available at a certain location and the starting trigger for a certain means of transportation is activated.

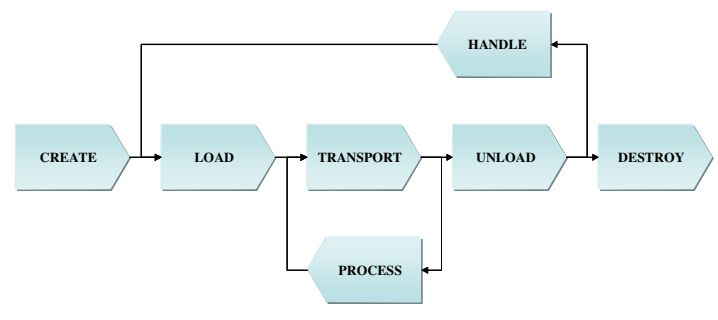

Figure 5: Simulation processes for flow items
Consecutively, the products are loaded onto the transport resource and then transported to the next stop on the route. If the next stop is a handling point, the products are unloaded and, if needed, prepared for the next shipment. In case of the next stop being a processing point, the idle time is applied and the transport continues. Upon arrival and unloading of the flow items at the destination plants, the respective product objects are destroyed in the simulation environment.

Throughout the simulation process, the running time and processing steps are logged and stored into a database. A historiography of the granulated simulation data in a database enables detailed and flexible analyses and a deduction of key performance indicators. With the evolved evaluation model which is discussed in the next section, the (logistic) results drawn from the simulation can be applied to calculations with data sources concerning emission behavior, for cost analyses, and for comparisons whether logistics targets have been met.

\section{Evaluation of Simulation Results}

The target criterions, which are relevant for the analysis of the designed co-operative multimodal logistics concepts can be summarized as

- the minimization of emissions,

- the reduction of logistics costs, and

- the increase of logistical competitiveness.

Therefore, the developed evaluation model is based on the calculation of key performance indicators (KPIs) for the three main target dimensions: Emissions, costs and competitiveness.

Regarding the analysis of emissions, it is in particular the intermodality of the models, which plays an important role when planning multimodal logistics chains. For this purpose, a selection of the most harmful emissions - namely $\mathrm{CO}_{2}, \mathrm{NO}_{\mathrm{X}}$, and amounts of particulates - is analyzed as key performance indicators. The emission levels are mainly dependent on the allocated type of transport resource and on the route, which means the distance covered by the predefined route profile. Diesel or electrical power consumption also play an important role in the output of emissions.

The cost evaluation model is somewhat more extensive and the assessment of total costs (1) can be subdivided into three individual cost calculations:

- $\quad$ transport costs (2),

- $\quad$ handling (i.e. transshipment) costs (3), and - inventory costs (4).

When it comes to transport costs, it is important that the model is based on the actual costs incurred, i.e., the overhead costs, road charges, customs clearance, and wage costs, and not on the transport tariffs charged by forwarding companies. The road charges are particularly difficult to determine due to various systems in the individual countries which is also an important influencing factor for the selection of transportation routes. 


$$
\begin{aligned}
& \mathrm{C}_{\text {Total }}=\mathrm{C}_{\text {Transport }}+\mathrm{C}_{\text {Handling }}+\mathrm{C}_{\text {Inventory }} \\
& \mathrm{C}_{\text {Transport }}=\mathrm{C}_{\text {Tsp.Truck }}+\mathrm{C}_{\text {Tsp.Train }}+\mathrm{C}_{\text {Tsp.Plane }}+\mathrm{C}_{\text {Tsp.Ship }} \\
& \mathrm{C}_{\text {Handling }}=\mathrm{L}\left(\mathrm{Q}_{\text {Chg. of Resource }} \cdot \mathrm{C}_{\text {Transshimpment (Chg. of Resource) }}\right) \\
& \mathrm{C}_{\text {Inventory }}=\mathrm{C}_{\text {Capital }} \cdot \mathrm{C}_{\text {Warehousing }}
\end{aligned}
$$

$$
\text { C...Cost, Q ... Quantity }
$$

The third criterion in evaluating simulation scenarios is the logistic competitiveness, which is made up of two key performance indicators:

- The ability to deliver: A measure of the extent to which the company can guarantee the logistical service requested by the customer - short delivery times compared to competitors are especially important for a high ability to deliver.

- The delivery reliability: Rates the service provision of the logistics process - it indicates the proportion of the complete and punctual deliveries compared to all delivery orders. (Vahrenkamp 2007).

The calculations of the aforementioned key performance indicators are performed independently from the simulation runs of the multimodal transportation scenarios. The logged simulation processing steps which are described in the previous section only serve as input for the computation of the evaluation model. In addition to this historiography, route profiles (types of roads with assigned maximum speeds), altitude profiles (incline), consumption profiles (diesel and power consumption differentiated by resource types), road charge calculation systems and other relevant parameters which are stored in a database, serve as a foundation for the calculations.

As the evaluation criteria of these three dimensions as the result of a simulation study may cause certain tradeoffs, an evaluation of a co-operative multimodal scenario of logistics chains can only be performed by comparing different scenarios and considering the pros and cons of all compromises. As an example, the fulfillment of logistical performance expectations will lead to the usage of flexible means of transport which are potentially more expensive and cause higher emissions due to an individual forwarding mode. The simulation and evaluation model offers a transparent and comparable analysis of the logistics system's dynamic behavior in all three dimensions and therefore provides a basis for decision making.

\section{HOLISTIC TRANSPORT OPTIMIZATION - A CASE STUDY}

As the preceding sections of this paper showed, simulation approaches can provide helpful techniques for supporting various decisions in co-operative multimodal logistics chains. The simulation model used in this approach can be used to evaluate arbitrary scenarios. Hence, a variety of decision-related issues can be answered like

- the optimal location of transshipment points,

- the preferred modes of transport for preliminary, main and subsequent legs,

or optimal routing options for main legs.

In order to validate the proposed simulation approach and illustrate the full potential of this technique in supporting co-operative transport decisions this chapter focuses on a case study describing possible optimizations for an automotive cluster in the region Timis in western Romania. Within these region, a considerable number of automotive suppliers are planning the exchange of goods with production sites mainly located in Germany, northern Italy or Spain on a local basis (i.e. without coordinating the transports with other suppliers). As a consequence, the analysis of the initial situation showed that all companies used direct road transport as their only means of transport. Another result of this initial study was that these transport capacities were only partly utilized which in turn shows a first potential for transport coordination.

\section{Designing simulation scenarios}

The identification of new co-operative logistics models dealing with the issues of the described situation should result in a reduction of transport costs as well as air pollution while maintaining a certain level of flexibility for the consignors. Standard logistics concepts like direct transport and part load concepts like milk run or groupage traffic were used as building blocks for alternative logistics scenarios. The use of a block train to handle the main leg is the common characteristic for all scenarios. The requirement to maximize the utilization of this main leg leads to the necessity of coordination of transport demands among the consignors in the region. The design of candidate scenarios for optimized coordinated logistics models is an iterative process requiring expert knowledge and the support of information technology. This approach has to consider the following topics:

- Identification of route sections which can be handled by a more efficient means of transport.

- Existence of potential partners for transport bundling within a region.

- Possibilities to optimally utilize transport carriers by joint planning activities.

- Prioritization of loads, given a carrier's capacity restrictions on the main leg.

- Methodology for handling transport backlogs infringing these capacity restrictions.

- Possibilities to alter transport frequencies in order to scale for different transport demands in the region.

As a result of these considerations, four alternative scenarios for co-operative multimodal logistics models were proposed:

1. Scenario 1 envisages the installation of a block train starting from Arad (Romania) with destinations in 
Stuttgart, Frankfurt and Wolfsburg (Germany) with two rotations per week (see fig. 6). Pre-carriage traffic for collecting goods from consignors as well as onward-carriage for distributing goods from the respective handling points in Germany to the consignees are designed as road-based direct transport. The shipments are assigned to the main leg in a "first-come-first-served" manner. Excess transport loads as well as loads for other destinations in Italy, Spain and Poland are handed over to direct carriers.

2. Scenario 2 is based on the first scenario but accounts for further bundling potential for direct traffic as well as for preliminary as well as subsequent legs. Here, the milk run concept is applied whenever an efficiency criterion yields this decision.

3. Scenario 3 is based on a shortened block train concept between Arad and Frankfurt twice a week. Pre-carriage as well as onward-carriage are designed as direct loads. This scenario accounts for a reduction of the rail-side complexity emerging from the first two scenarios.

4. Scenario 4 also builds upon the shortened block train concept but further bundles the remaining road traffic similar to scenario 2 .

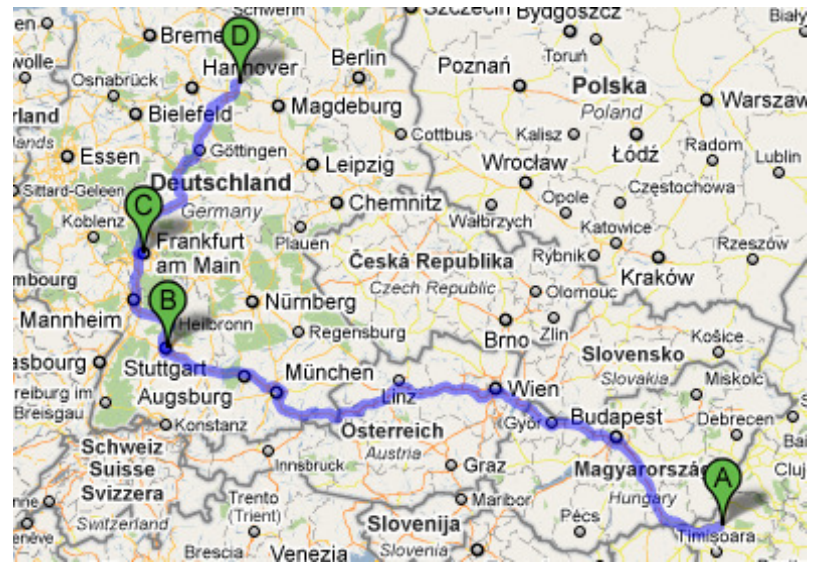

Figure 6: Main leg in scenarios 1 and 2

\section{Simulation run and evaluation of results}

As it is obvious from the above considerations, the holistic evaluation of the proposed scenarios represents a complex decision problem. In the proposed approach, the simulation model accounts for various types of transport- and handling-related costs, environmental factors associated with road traffic as well as with rail transport in the respective countries (usage of diesel locomotives, mixture of power sources, etc.) and logistical performance measures. The simulation study analyzed the shipment volumes and frequencies of seven automotive suppliers in the Timis region within a timeframe of ten subsequent weeks.

As a result, the proposed simulation approach shows the potential for optimization within the three distinct perspectives of economic as well as environmental and logistics factors.

The descriptive statistics of used transport concepts already outline the implications for these three dimensions: The share of tonnage handled by direct traffic decreases from $95.4 \%$ in the initial model to $35.1 \%$ in scenarios 1 and 2 and even further to $23.1 \%$ in scenarios 3 and 4. Against that, the shared intermodal transport concepts in the first two scenarios accounts for $62.8 \%$ and $66.3 \%$ in scenarios $1 / 2$ and $3 / 4$, respectively. This shift of transport paradigms results in $59 \%$ of tonne kilometers being transported by rail (compared to $0 \%$ in the initial scenario).

As it is obvious from the reduction of road-based traffic, there would be a tremendous ecological impact which reduces $\mathrm{CO}_{2}$ emissions by nearly $40 \%$ and $\mathrm{NO}_{\mathrm{x}}$ even by $50 \%$ (see fig. 7). This effect is still influenced by the high share of caloric production of traction power in CEE countries. However, this only weakly affects the environmental results without altering them.

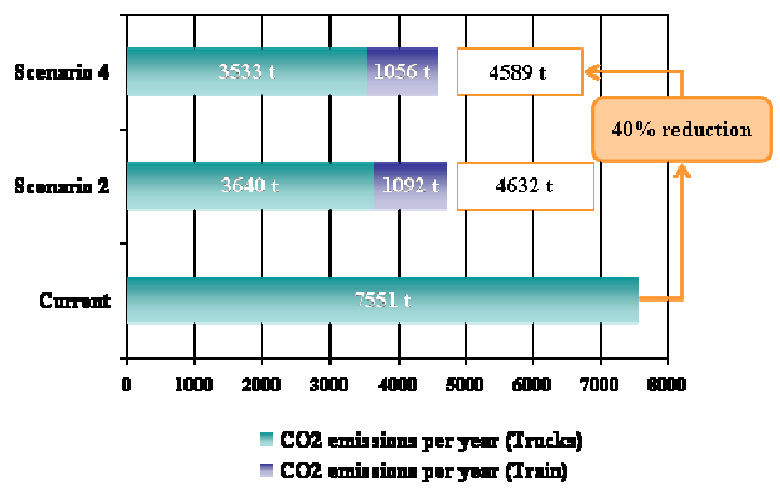

Figure 7: Reduction of $\mathrm{CO}_{2}$ emissions

Regarding the economic impact of the proposed logistics models one can observe a slight reduction of transportation costs for scenarios 1 and 2 (- 1.2\% and $3.6 \%$, respectively). When reducing the complexity of rail transport in scenarios 3 and 4 the full potential of co-operative transport bundling can be tapped. With the shortened block train concept, significant cost reductions of $-16.5 \%$ and $-14.2 \%$ in scenarios 3 and 4 become possible. As a sensitivity analysis shows, this result of the latter two scenarios becomes robust under limited variations of alternative transportation costs as well as shipment volumes. The development of fuel prices as the main driver for road-side transportation tariffs give rise to the expectation that this relation will change in favor of rail-based transportation in the future. Finally, the logistics perspective can be analyzed by the simulation approach: Due to increased handling requirements and the periodical manner of rail transport the throughput times for a single shipment rise by at least $21 \%$ (scenario 1). In a worst case scenario (scenario 2) the combined transport will take $38 \%$ longer than the direct load equivalent. However, these figures are based on the assumption that the consignees 
and consignors of the shipments do not adapt their manufacturing processes to the framework conditions of the new logistics models.

\section{CONCLUSIONS AND OUTLOOK}

This article described a simulation-based approach to evaluate different logistics models based on coordinated intermodal concepts. The novel approach of separating the domain model of logistics concepts from the calculation of Key Performance Indicators (KPIs) enables a holistic quantification of manifold impacts arising from a concept shift between road and rail transportation within an economic, an ecological as well as a logistical dimension.

The case study of a Romanian automotive cluster illustrated the analytic complexity of the problem as well as decision-supporting possibilities which are offered by the simulation technique. By using a domain-specific modeling approach the simulation framework was able to quantify the extensive potential which is offered by coordinated planning of transport chains.

Whilst the four candidate scenarios based on multimodal transport concepts yield tremendous optimization potentials with respect to the ecologic perspective and considerable possibilities to reduce transportation costs, they result in higher throughput times. The latter result can be explained based on the assumption that consignors and consignees do not adapt their manufacturing and sourcing processes to the possibilities of the multimodal transport chain. However, for fully tapping the potential of multimodal transport means also with respect to the generation of logistical advantages, it is necessary to adjust the planning processes for manufacturing plants on either side of the transport chain to the forwarding process. This could be achieved for example by explicitly integrating cost saving effects of multimodal transportation into manufacturing lot planning techniques. This in turn could result in a better timing of manufacturing output with respect to periodically scheduled block trains or other multimodal transportation concepts.

\section{REFERENCES}

Brauer, K.M.; Krieger, W. 1982. Betriebswirtschaftliche Logistik. Berlin.

Campbell, J. 1990. "Freight consolidation and routing with transportation economies of scale." Transportation Research Part B 24, No. 5, 345-361.

Feldmann, K., Rottbauer, H., Roth, N. 1996. "Relevance of Assembly in Global Manufacturing." Annals of the CIRP 45, No. 2, 545-552.

Kinkel, S., Lay, G., Maloca, S. 2004. Produktionsverlagerungen ins Ausland und Rückverlagerungen. Report on the BMF research project no. 8/95, Fraunhofer-ISI, Karlsruhe.

Nordgren, William B. 2003. Flexsim Simulation Environment. In Proceedings of the 2003 Winter Simulation Conference, Volume 1, eds. Stephen E. Chick,
Paul J. Sánchez, David Ferrin, and Douglas J. Morrice, 197-200.

Pfohl, H.-C. 2004. Logistikmanagement: Konzeption und Funktionen, 2., überarbeitete und erweiterte Ausgabe. Springer-Verlag, Berlin.

Rösler, O.M. 2003. Gestaltung von kooperativen Logistiknetzwerken: Bewertung unter ökonomischen und ökologischen Aspekten. Deutscher Universitäts-Verlag, Wiesbaden.

Sihn, W., Palm, D., Matyas, K., Kuhlang, P. 2006. Automotive Region Eastern Europe-AREE: Chancen und Potentiale des "Detroit des Ostens" für Automobilzulieferer, Fraunhofer Austria, Vienna.

Sihn, W., Palm, D., Schmitz, K, Leitner, R. 2009. Automotive Region Central and Eastern Europe Produktionsstrukturen von Automobilherstellern und ihrer Zulieferer. Fraunhofer Austria, Vienna.

Simchi-Levi, D., Kaminsky, Ph., Simchi-Levy, E. 2007. Designing and Managing the Supply Chain - Concepts, Strategies and Case Studies, $3^{\text {rd }}$ edition. Irwin McGrawHill, Boston.

Taniguchi, E., Thompson, R.G., Yamada, T., Van Duin, R. 2001. City Logistics: Network Modelling and Intelligent Transport Systems. Pergamon, Oxford.

Trip, J., Bontekoning, Y. 2002. "Integration of small freight flows in the intermodal transport system." Journal of Transport Geography 10, 221-229.

Vahrenkamp, R. 2007. Logistik: Management und Strategien, 6.Auflage. Oldenbourg Wissenschaftsverlag, München.

Wiendahl, H.-P., Lutz, S. 2002. "Production in Networks." Annals of the CIRP 51, No. 2, 573-586.

\section{AUTHOR BIOGRAPHIES}

V-Research is an Austrian competence center for industrial research and development. In the research field "Process Engineering for Construction, Manufacturing and Logistics" the research center focuses on methods to support complex decision making in manufacturing and logistics processes.

Christian Hillbrand is head of the research area „Technical Logistics” at V-Research and director of the research program "ProDSS" (Integrated Decision Support Systems for Industrial Processes). He holds a $\mathrm{PhD}$-degree in business information systems from the University of Vienna.

Susanne Schmid is research assistant and project manager at V-Research. Her main research areas include the conception, modeling and development of simulation models. 